\title{
Cerebral Palsy: Soup to Nuts
}

\author{
Elizabeth Moberg-Wolff • Jill Meilhan • \\ Michael Ward • Deborah McLeish
}

Published online: 26 March 2013

(c) Springer Science + Business Media New York 2013

\begin{abstract}
Children with cerebral palsy have variable medical and developmental needs, which impact their ability to grow and function independently. Therapy interventions for fine motor skills, speech and mobility skills can be of benefit. The importance of optimizing vision, hearing, nutrition, and spasticity control also impacts learning, growth and function as well as reducing secondary complications such as fractures. This article reviews recent literature for clinical updates that impact these areas.
\end{abstract}

Keywords Cerebral palsy · Neuroprosthesis - SEMLs · Augmentative communication - Sialorrhea - Bone density . Osteoporosis · Therapy · Orthotic devices · Disabled child . Caregivers · Cognition disorders · Vision disorders . Spasticity $\cdot$ Hearing impairment $\cdot$ Constraint induced therapy $\cdot$ Hand therapy $\cdot$ Botulinum toxin

\section{Orthotics}

\section{Lower Extremity}

Plastic AFOs have become the standard of care for ambulatory children with cerebral palsy who have foot drop [1••], as they are lighter and offer more control than the metal upright braces used in the past. A variety of different plastics are available to choose from, and various articulating joints and carbon graphite composites are adding to fabrication flexibility. AFOs may be rigid or

E. Moberg-Wolff $(\bowtie) \cdot$ J. Meilhan · M. Ward · D. McLeish Pediatric Rehabilitation Medicine Associates, LLC, 3815 N Brookfield Rd Ste 104-264, Brookfield, WI 53045, USA e-mail: emoberg@pedsrehab.org allow some dorsiflexion during the second rocker, as with hinged or posterior leaf spring models. A slight forward inclination of the tibia appears to be optimal.

The majority of studies show increased gait velocity with AFO use. Solid AFOs have been shown to improve ground reaction force and skeletal alignment of the foot and ankle. They also reduce power generation and absorption at the ankle, but this may be an acceptable trade-off. AFOs may decrease the metabolic cost of walking and maintain gastrocsoleus length. They are all inherently passive in nature. AFOs are commonly prescribed for children with GMFCS levels IV and V for use in standers and for position on wheelchair footplates, but there is no research evidence for these uses.

Carbon fiber AFOs are available in pediatric sizes (Kiddie Gait, Toe-off, Noodle). They may offer a more physiologic gait, are lightweight, and may be more aesthetically pleasing to some. Research is limited in pediatrics and mostly study a weak, rather than spastic, drop foot, such as in CMT or spina bifida.

Night stretching splints for improving hamstring or gastrocsoleus range of motion are helpful and may be less disruptive to sleep than previously thought. While children with cerebral palsy frequently have sleep disturbance for multiple reasons, use of night orthoses did not increase sleep disturbance in a recent study [2]. Parental personality, parental sense of burden, and parental feelings of competence were more significant variables influencing nighttime wear. Helping parents feel competent and successful regarding use of the orthoses may improve compliance.

\section{Neuroprosthesis}

Current research suggests common fibular nerve-stimulating neuroprostheses (Walkaide, Bioness) may have potential for 
many ambulatory children with cerebral palsy. The Walkaide device triggers ankle dorsiflexion by using a tilt sensor that detects knee flexion at the pre-swing phase, allowing for ankle dorsiflexion throughout the swing phase. It allows for active plantar flexion during the third rocker. It is customprogrammed for each individual $[3 \cdot, 4,5]$. The Bioness in contrast is triggered by a sensor at the heel detecting heel strike. There is no published pediatric research for this device. Current articles indicate that the neuroprostheses are well tolerated, and increase tibialis anterior muscle thickness and cross-sectional area, which was maintained for at least 3 months to the end of the trial [3•].

\section{Upper Body Orthoses}

Upper body orthoses have evolved from firm plastic shells, to include softer Lycra-based products, which may benefit children with sensory and mild realignment issues. Evidence from studies on these garments (SPIO, Theratog, Dynamic Realignment Orthosis, Dynamic Movement Orthosis, Benik) is difficult to assess due to the variability in outcomes measured, types of orthoses used, and types of $\mathrm{CP}$ in the subjects [1••]. Assessment of their cost/insurance reimbursement, ease of donning and doffing, and ability to provide the appropriate amount of support needs to be matched to each child's needs $[6,7]$.

\section{Spasticity}

Muscle spasticity may cause major functional difficulties for many children with cerebral palsy. Spasticity may be modulated by injectable botulinum toxins, and by oral and intrathecal medications such as baclofen. Two serotypes of botulinum toxin preparations are available for medical use, $\mathrm{A}$ and B. Both block neuromuscular activity by acting as acetylcholine release inhibitors, but they vary in their amino acid sequences. They are not interchangeable, even within a specific serotype. It is important to recognize their similarities and differences in order to avoid over- or underdosing. For instance, there are three botulinum (BoNT) toxin A preparations commercially available in the USA; incobotulinumtoxinA, abobotulinumtoxinA, and onabotulinumtoxinA. They each have different potencies per unit, different dosage units, and different production, protein and stability parameters [8••]. RimabotulinumtoxinB also has a different clinical profile, with an anticholinergic systemic effect in some patients. The dry mouth that may result can be beneficial for those with sialorrhea, or have an adverse effect for others. Thus, choosing the most appropriate medication for the patient's needs is important [9]. No BoNT are FDA-approved for pediatric use in the USA, although they are widely used off-label and studies are ongoing [9]. Current literature is supportive of the improved ease of care and comfort [10].

It is critical to understand that if switching between preparations or serotypes, dosage cannot be interchanged without consideration for the differences in dosing units, and potential clinical effect. A patient, who has accommodated to one serotype, should start at the initial dosing parameters of a new serotype, in order to avoid overdosing. While there are no commonly recognized ratios for changing toxin strains, work is being done in that area [11].

Immunoresistance is a concern for patients that may be receiving injections over their lifetime. They can develop resistance to a toxin serotype, due to antibody formation. The incidence of this for type A serotype varies from 3 to $23 \%$ [10]. Switching to another serotype can once again improve clinical effectiveness. Avoidance of immunoresistance is thought to be achieved by the lowest dosing possible, at the longest interval possible. Using a preparation with the least protein content may also be helpful. Preparations of type A have been altered over the years to reduce protein content. Incobotulinum is the only brand currently available with no protein associated with the toxin [12].

Toxin use in children is expanding to not just limb or cervical muscles but also as treatment for overactive bladder, drooling, esotropia, GI dysmotility, and migraine/ pain $[13,14,15 \cdot 16]$. As various physicians may end up injecting the same child, it is imperative that they communicate and "share" dosing at appropriate intervals, so as to avoid iatrogenically overdosing or inducing resistance.

\section{Orthopedic Surgery}

\section{SEMLS}

Single event multilevel surgery is defined as two or more bony or soft tissue procedures at two or more anatomic levels during one operative procedure. Prior to the advent of SEMLS, orthopedic surgeries followed the pattern of Achilles tendon lengthening 1 year, hamstring lengthening the next, and finally proximal femoral derotation osteotomies with hip adductor and psoas lengthening in the third year; the so-called "birthday surgeries". The child seemed to be continuously recovering from surgery.

Single event multilevel surgery was initiated to deal with all the common malalignments at once, in the hope that post-surgery rehabilitation would more quickly result in improved gait and posture. It is usually undertaken when less invasive treatments, such as bracing, casting, botulinum toxin injections, and/or intrathecal baclofen have been maximized. Bony deformity corrections usually address the most common combination of femoral anteversion and external tibial torsion. Soft tissue procedures 
usually address loss of joint range of motion by muscle/ tendon lengthening.

Good short-term and long-term benefits have been shown 5 and 10 years post-procedure [17, 18••, 19]. Specific areas of improvement over baseline that remained at 10 years post-surgery included stride length, knee flexion angle, and walking speed [19]. Studies have even shown an improvement in GMFCS level for those in levels II-IV. Controversies exist regarding the role of instrumented gait analysis, distal hamstring lengthening, "dosing" of gastrocsoleus lengthening, rectus femoris transfers, and best treatment for anterior pelvic tilt $[17,18 \bullet \bullet, 19-24]$.

\section{Augmentative Communication}

Augmentative communication is receiving increased attention due to the ready availability of touchscreen phones and tablets. Families are becoming active consumers and purchasing devices themselves. AAC applications are available from a wide variety of programmers. Unfortunately, most of the applications are based on AAC designs from the 1980s and 1990s. There is still research to be done in many areas, including the best representation of language concepts. For example, traditionally, a still photo of a person running or even a stylized symbol of a person running were used on a grid. Current technology would allow a video of someone running which might convey the concept better to a very young child. It might be better yet if the person running is someone the child knows [25••].

Navigation and selection techniques are weighted toward children with typically developing vision and motor skills. Research is needed to determine the best methods to navigate through a menu and to make a selection for children with motor, perceptual, and cognitive difficulties.

Programming specific vocabulary and communication concepts is still difficult for parents and educators to do quickly. And while the potential exists to integrate school curricular content onto a tablet AAC, there is currently no easy way to accomplish this.

\section{Sialorrhea}

Drooling prevalence was self-reported at $40 \%$ in one population study [23]. This can lead to skin irritation, social isolation, and difficulty with articulate speech [26]. The use of salivary gland botulinum toxin injections as a treatment for drooling has been systematically reviewed and a temporary positive impact on this problem has been identified, although adverse events ranged from 2 to $41 \%$ across studies included dysphagia, dysarthria, and thickened salivary viscosity [27]. Oral glycopyrrolate, now available in an oral solution, has had demonstrated efficacy in several randomized trials, starting doses at $0.02 \mathrm{mg} / \mathrm{kg}$ TID and increasing up to $0.1 \mathrm{mg} / \mathrm{kg}$ TID, with maximum dose $3 \mathrm{mg}$ [28]. Transdermal scopolamine can also be effective in reducing salivation in children [29]. No controlled trials have been conducted on management options of physical and behavioral interventions, or intra-oral appliances for drooling botulinum toxin injections, or surgery [15•].

\section{Constraint-Induced Therapy}

Therapy classically involves structured shaping and repetitive task practice of impaired upper limb use in children with hemiplegia, facilitated though some type of restriction of use of the more functional limb (casts, gloves, etc.). Various adaptations of this technique have been studied in pediatric populations for over 20 years, with multiple critical reviews [30 ]. The feasibility of CIMT with children is now well established, but there are many questions remaining about how to best apply this approach.

Several recent randomized clinical trials have compared CIMT with intensive bimanual training (BIM) [31-37] or intensive traditional occupational therapy methods (IOT) [38, 39]. All centers reported functional gains for CIMT, BIM, and IOT groups. The CIMT groups generally had more rapid, early changes in the quality of unilateral hand function, and the BIM groups had better bimanual function, which may assist in better achievement of functionally meaningful goals [32, 33, 36, 37]. However, 6-month and 1-year follow-up assessments demonstrated fairly similar overall outcomes for all groups, with sustained improvements in function. One randomized study identified that electrical stimulation enhanced outcome in the CIMT group [39].

Research clearly supports the efficacy of episodes of intensive occupational therapy as functionally beneficial for children with hemiplegic cerebral palsy, regardless of the specific therapy methods used. Prediction of which age or severity level does best with intensive therapy has not been consistent across studies. Recent studies comparing dosages of CIMT have not seen a significant difference between 3 and $6 \mathrm{~h} /$ day therapy programming during the weeks of treatment [40]. This is inconsistent with previous data suggesting that $90 \mathrm{~h}$ of treatment is superior to $60 \mathrm{~h}$ [41]. The complex relationship between botulinum toxin CIMT and BIM also requires further study. The ideal outcome for each individual may come from sequential combinations of several of these interventions.

\section{Sensory Integration}

The influence of sensory abilities on functional performance for children with hemiplegic cerebral palsy is an 
area where new information is emerging. Spatial tactile deficits have been reported as accounting for $30 \%$ of the variance in upper limb motor function in children with unilateral cerebral palsy (UCP) [42]. Compared to typically developing children, $40 \%$ of children with UCP had tactile registration and perception deficits, $37 \%$ just had perceptual deficits, and only $23 \%$ had no perceptual deficits [43]. Functional studies of the somatosensory cortex in children with UCP demonstrate less lateralization of sensory processing and more ipsilateral activation during functional movements and sensory stimulation [44, 45]. Mirror therapy has been tried with UCP, providing visual mirror feedback from the more functional limb in training bimanual targeting. In the experimental setting, mirror therapy has demonstrable benefits [46]. The place of this treatment modality in UCP has yet to be defined. Of note, these sensory differences likely also underlie an odds ratio of 27.33 for left-handedness in comparing children with diplegic cerebral palsy to children with typical development [47].

Children with cerebral palsy are also at risk for abnormalities in visual processing, including refractive errors, strabismus, abnormal saccadic movements, and reduced visual acuity [48•*]. In one study, $83 \%$ of children with good visual acuity, but a history of prematurity and perinatal hypoxia, had cerebral visual impairment identified [49].

Though it has less impact on motor function, hearing loss is also important to recognize in addressing rehabilitation concerns for children with cerebral palsy. There have limited population studies of this concern, estimating an incidence around $10 \%$, with birth weight a significant factor $[50,51]$.

\section{Nutrition}

Gastrostomy or jejunostomy tube feedings and their impact on nutrition and growth restriction are important concepts in children with cerebral palsy, who often have failure to thrive (REF). Among children with CP-GMFCS IV and V (groups at greatest risk for feeding difficulties), there is a clear association between low prevalence of gastrostomy tube feeding and more severe growth restriction [52].

While pediatric formulas typically contain adequate vitamin supplementation and calories, adjustments for specific nutrients not well absorbed in children with $\mathrm{G}$ or $\mathbf{J}$ tube feedings, or which they may need in excess due to risks related to their immobility, may be needed. Copper is a nutrient that is absorbed primarily in the stomach and the duodenum, and whose uptake can be inhibited by zinc and iron supplementation [53, 54]. Copper deficiency may cause hypochromic anemia, sensory ataxia, peripheral neuropathy, and myelopathy. In children with special needs, these diagnosis may be attributed to other factors, and not be treated adequately because malabsorption was not recognized as a cause.

Nutrient deficiencies can also develop in tube-fed individuals, particularly when formula intake is limited due to excessive weight gain/low calorie requirement. For Jevity 1.0 for example, if a child receives fewer than $1,400 \mathrm{cal}-$ ories a day, they do not meet DRI (daily required intake) requirements. Cutting down calories by limiting formula intake without changing the composition of the formula can result in nutrient deficiencies, including protein.

For exclusively tube-fed individuals, in addition to following weight (and length or arm span or knee height), the following may be important to monitor when nutrient compromise is suspected: albumin, pre-albumin, zinc, selenium, magnesium, and copper (with the latter particularly in individuals fed via $\mathrm{J}$ tube). If caloric intake must be decreased because of excessive weight gain, the 1.2 formulas provide better nutrient density than the 1.0 formulas and should be considered.

The Dietary Reference Intakes, Food and Nutrition Board, Institute of Medicine, National Academies list recommend intake of various nutrients by life-stage group. A number of nutrients (calcium, phosphorus, magnesium) have a notable increase at age 9. Depending on total formula intake and what contribution to nutrient intake there may be from oral feedings, this may be the age to change children from pediatric formulas to adult formulas.

\section{Osteopenia}

The definition of osteoporosis for children and adolescents "requires the presence of both a clinically significant fracture history and low bone mineral content (BMC) or bone mineral density" [55]. A clinically significant fracture history is one or more of the following:

a. Long bone fracture of the lower extremities.

b. Vertebral compression fracture.

c. Two or more long-bone fractures of the upper extremities.

When technically feasible, patients should have spine and total body less head (TBLH) BMC and areal bone mineral density (BMD) measured prior to initiation of bone-active treatment, and to monitor treatment.

In children with chronic immobilization (e.g., cerebral palsy), spine and TBLH BMC and areal BMD are most often measured at fracture presentation. 
In children, spine and TBLH BMC and areal BMD results should be adjusted for absolute height or height age, or compared to pediatric reference data that provide age-, gender-, and height-specific $Z$ scores. This differs from adults whose BMD is measured in age-compatible $\mathrm{T}$ scores.

The hip (including total hip and proximal femur) is not a reliable site for measurement in growing children due to significant variability in skeletal development and lack of reproducible region of interest. The distal femur is a more effective measurement.

A systematic review of clinical practice guidelines for treatment of osteoporosis and prevention of fragility fractures in children with cerebral palsy was done in 2012 [56].

Regarding weight-bearing activity intervention, six studies met criteria and were reviewed. There were inadequate data to support a recommendation for weight-bearing activities as an effective intervention for improving BMD or for decreasing fragility fractures in children and young people with CP. No significant adverse events were reported, however, and there are other important benefits to standing that must be considered (contracture reduction, etc.).

Vitamin D supplementation (1,25 OH2-D3) and calcium may be beneficial for improving BMD, although their impact on fracture rates is unknown. No significant adverse events are typical secondary to the vitamin $\mathrm{D}$ use, so the recommendation for supplementation of up to $1,000 \mathrm{IU}$ of Vitamin D was recommended to allow the body to achieve levels above $50 \mathrm{nmol} / \mathrm{L}$.

Spot urine calcium/osmolality was recommended at baseline and 6-12 months after starting supplementation to help follow for any evidence of hypercalciuria. The report also indicated that a spot calcium/creatinine can be elevated in children with decreased muscle mass who may have low creatinine level.

The review cited five studies evaluating bisphosphonates (4-IV pamidronate, and 1-oral risedronate) in children, with evidence of probable effectiveness of bisphosphonate use to increase BMD in children with CP. However, they did not recommend biphosphonates in children with low BMD as a preventative measure until further evidence was available. The focus instead should be clinical treatment, if, despite correction of Vitamin D levels and calcium treatment, repeated fractures are still being sustained.

Disclosure E Moberg-Wolff is an employee of Pediatric Rehabilitation Medicine Associates, LLC (Milwaukee, WI) and has received consulting fees from Merz; J Meilahn is an employee of Marshfield Clinic (Marshfield, WI) and has received consulting fees from Allergan; M Ward is an employee of the University of Wisconsin Hospital and Clinics (Madison, WI) and declares no conflicts of interest; and DLP McLeish is an employee of the University of Wisconsin Hospital and Clinics (Madison, WI) and declares no conflicts of interest.

\section{References}

Papers of particular interest, published recently, have been highlighted as:

- Of importance

•• Of major importance

1. •• Morris C, Bowers R, Ross K, et al. Orthotic management of cerebral palsy: recommendations from a consensus conference. NeuroRehabilitation. 2011;28(1):37-46. This reference gives a nice overview of current use and benefits of orthotics from a consensus conference.

2. Mol E.M., Monbaliu E, Ven M, Vergote M, Prinzie P: The use of night orthoses in cerebral palsy treatment: Sleep Disturbance in children and parental burden or not? Res in Dev Disabil 2012 Mar-Apr; 33(2): 341-349.

3. - Prosser LA, Curatalo LA, Alter KE, Damiano DL. Acceptability and potential effectiveness of a foot drop stimulator in children and adolescents with cerebral palsy. Dev Med Child Neurol. 2012;54(11):1044-9. This study demonstrates that pediatric patients with cerebral palsy can successfully wear, and benefit from, a commercially available FES foot drop device.

4. Damiano DL, Prosser LA, Curatalo LA, Alter KE. Muscle plasticity and ankle control after repetitive use of a functional electrical stimulation device for foot drop in cerebral palsy. NeuroRehab Neural Repair. 2012;4:1-8.

5. Meilahn JR. The tolerability and effectiveness of a footdrop neuroprosthesis. PM R. 2013.

6. Flanagan A, Krzalz J, Peer M, Johnson P, Urban M. Evaluation of short-term intensive orthotic garment use in children who have cerebral palsy. Pediatr Phys Ther. 2009;21:201-4.

7. Elliott CM, Reid SL, Alderson JA, Elliott BC. Lycra arm splints in conjunction with goal-directed training can improve movement in children with cerebral palsy. NeuroRehabilitation. 2011;28(1): 47-54.

8. •• Peng Chen Z, Morris J, Rodriquez RL, et al. Emerging opportunities for serotypes of botulinum neurotoxins. Toxins. 2012;4(11):1196-222. A thorough basic science review of the pathophysiology, serotypes, and potential uses of botulinum neurotoxins.

9. Dahan-Oliel F, Kasaai B, Montpetit K, Hamdy R. Effectiveness and safety of botulinum toxin type $\mathrm{A}$ in children with musculoskeletal conditions: what is the current state of evidence. Int $\mathbf{J}$ Pediatr. 2012;2012:898924.

10. Thorley M, Donaghey S, Edwards P, et al. Evaluation of the effects of botulinum toxin A injections when used to improve ease of care and comfort in children with cerebral palsy whom are non-ambulant: a double blind randomized controlled trial. BMC Pediatr. 2012;9(12):120.

11. Kim SB, Ban B, Jung KS, Yang GH. A pharmacodynamic comparison study of different botulinum toxin type a preparations. Dermatol Surg. 2013;39(1 Pt 2):150-4.

12. Kaňovský P, Slawek J, Denes Z, Platz T, Comes G, Grafe S, Pulte IJ. Efficacy and safety of treatment with incobotulinum toxin A (botulinum neurotoxin type A free from complexing proteins; NT 201) in post-stroke upper limb spasticity. J Rehabil Med. 2011;43(6):486-92.

13. McDowell DT, Noone D, Tareen F, Waldron M, Quinn F. Urinary incontinence in children: botulinum toxin is a safe and effective treatment option. Pediatr Surg Int. 2012;28(3):315-20.

14. Schroeder AS, Huss K, Blaschek A, Koerte IK, Zeycan B, Roser T, Langhagen T, Schwerin A, Berweck S, Reilich P, Schaefer J, Straube A, Heinen F. Ten-year follow-up in a case series of integrative botulinum toxin intervention in adolescents with 
chronic daily headache and associated muscle pain. Neuropediatrics. 2012;43(6):339-45.

15. - Walshe M, Smith M, Pennington L. Interventions for drooling in children with cerebral palsy. Cochrane Database Syst Rev. 2012;14(11):CD008624. This review discusses all option for sialorrhea management, despite the lack of controlled studies looking at their efficacy.

16. Couser NL, Lambert SR. Botulinum toxin a treatment of consecutive esotropia in children. Strabismus. 2012;20(4):158-61.

17. Thomason P, Selber P, Graham HK. Single event multilevel surgery in children with bilateral spastic cerebral palsy: a 5 year prospective cohort study. Gait Posture. 2013;1:23-8.

18. • McGinley JL, Dobson F, Ganeshalingam R, Shore BJ, Graham HK. Single-event multilevel surgery for children with cerebral palsy: a systematic review. Dev Med Child Neurol. 2012; 54(2):117-28. This is an excellent review articles on the status of SEMLs, its long term benefits and the reason SEMLs should be state of the art for orthopedic surgeries in children with cerebral palsy.

19. Hughes CX, Gardner R, Pyman J, Toomey K, Gargan MF. Orthopedic assessment and management of cerebral palsy. Orthop Trauma. 2012;26(4): 280-291.

20. Thomason P, Rodda J, Sangeux M, Selber P, Graham K. Management of children with ambulatory cerebral palsy: an evidencebased review. J Pediatr Orthop. 2012;32(Suppl 2):S182-6.

21. Sung KH, Chung CY, Lee KM, Akhmedov B, et al: Long term outcome of single event multilevel surgery in spastic diplegia with flexed knee gait. Gait Posture. 2012. doi:10.1016/j.gaitpost. 2012.09.011.

22. Narayamon UG. Management of children with ambulatory cerebral palsy: an evidence- based review. J Ped Ortho. 2012; 32(Suppl 2):S172-81.

23. Thomason P, et al. SEMLS in children with spastic dysplegia. J Bone Joint Surg Am. 2011;93:451-60.

24. Gannotti ME, Gorton GE III, Nahorniak MT, Masso PD. Walking abilities of young adults with cerebral palsy: changes after multilevel surgery and adolescence. Gait Posture. 2010;32(1):46-52.

25. • Light J, McNaughton D. Supporting the communication, language, and literacy development of children with complex communication needs: state of the science and future research priorities. Assist Technol. 2011;24(1):34-44. This article reviews the current status of $A A C$ with an excellent assessment of current technology, such as the iPad. The author provides clear descriptions of current limitations in $A A C$, as well as stimulating recommendations for future use and research.

26. Reid SM, McCutcheon J, Reddihough DS, Johnson H. Prevalence and predictors of drooling in 7- to 14-year-old children with cerebral palsy: a population study. Dev Med Child Neurol. 2012;54:1032-6.

27. Rodwell K, Edwards P, Ware RS, Boyd R. Salivary gland botulinum toxin injections for drooling in children with cerebral palsy and neurodevelopmental disability: a systematic review. Dev Med Child Neurol. 2012;54:977-87.

28. Zeller RS, Lee HM, Cavanaugh PF, Davidson J. Randomized phase III evaluation of the efficacy and safety of a glycopyrrolate oral solution for the management of chronic severe drooling in children with cerebral palsy or other neurologic conditions. Ther Clin Risk Manag. 2012;8:15-23.

29. Mato A, Limeres J, et al. Management of drooling in disabled patients with scopolamine patches. Br J Clin Pharmacol. 2010; 69(6):684-8.

30. - Sakzewski L, Ziviani J, Boyd R. Systematic review and metaanalysis of therapeutic management of upper-limb dysfunction in children with congenital hemiplegia. Pediatrics. 2009;123(6): e1111-22. This group of authors compares participation of hemiplegic pediatric patients using CIMT vs. bimanual therapy, using an intense model of CIMT.

31. Sakzewski L, Ziviani J, Boyd R. Best responders after intensive upper limb training for children with unilateral cerebral palsy. Arch Phys Med Rehabil. 2011;92(4):578-84.

32. Sakzewski L, Ziviani J, Abbott DF, Macdonnell RA, Jackson GD, Boyd R. Randomized trial of constraint induced movement therapy and bimanual training on activity outcomes for children with congenital hemiplegia. Dev Med Child Neurol. 2011;53(4): 313-20.

33. Sakzewski L, Ziviani J, Abbott DF, Macdonnell RA, Jackson GD, Boyd R. Participation outcomes in a randomized trial of 2 models of upper-limb rehabilitation for children with congenital hemiplegia. Arch Phys Med Rehabil. 2011;92(4):531-9.

34. Sakzewski L. Equivalent retention of gains at 1 year after training with constraint-induced or bimanual therapy in children with unilateral cerebral palsy. Neurorehabil Neural Repair. 2012; 25(7):664-71.

35. Gordon AM, Hung YC, Brandao M, Ferre CL, Kuo HC, Friel K, Petra K, Chinnan A, Charles JR. Bimanual training and constraint-induced movement therapy in children with hemiplegic cerebral palsy: a randomized trial. Neurorehabil Neural Repair. 2011;25(8):692-702.

36. Fedrizzi E, Rosa-Rizzotto M, Turconi AC, Pagliano E, Fazzi E, Visona Dalla Pozza L. Unimanual and bimanual intensive training in children with hemiplegic cerebral palsy and persistence in time of hand function improvement: 6-month follow-up results of a multisite clinical trial. J Child Neurol. 2013;28(2):161-75.

37. Facchin P, Rosa-Rizzotto M, Visona Dalla Pozza L, Turconi AC, Pagliano E, Signorini S, Tornetta L, Trabacca A, Fedrizzi E. Multisite study comparing the efficacy of constraint-induced movement therapy with that of bimanual intensive training in children with hemiplegic cerebral palsy: post-intervention results. Am J Phys Med Rehabil. 2011;90(7):539-53.

38. Wallen M, Ziviani J, Naylor O, Evans R, Novak I, Herbert R. Modified constraint-induced therapy for children with hemiplegic cerebral palsy: a randomized trial. Dev Med Child Neurol. 2011;53(12):1091-9.

39. Xu K, Wang L, Mai J, He L. Efficacy of constraint-induced movement therapy and electrical stimulation on hand function of children with hemiplegic cerebral palsy: a controlled clinical trial. Disabil Rehabil. 2012;34(4):337-46.

40. DeLuca SC, Case-Smith J, Stevenson R, Ramey SL. Constraintinduce movement therapy (CIMT) for young children with cerebral palsy: effects of therapeutic dosage. J Pediatr Rehabil Med. 2012;5(2):133-42.

41. Gordon AM. To constrain or not to constrain, and other stories of intensive upper extremity training for children with unilateral cerebral palsy. Dev Med Child Neurol. 2011;53(S4):56-61.

42. Auld ML, Boyd RN, Mosely GL, Ware RS, Johnston LM. Impact of tactile dysfunction on upper-limb motor performance in children with unilateral cerebral palsy. Arch Phys Med Rehabil. 2012;93(4):698-702.

43. Auld ML, Boyd RN, Mosely GL, Ware RS, Johnston LM. Tactile function in children with unilateral cerebral palsy compared to typically developing children. Disabil Rehabil. 2012;34(17): 1488-94.

44. Van de Winckel A, Klingels K, Bruyninckx F, Wenderoth N, Peeters R, Sunaert S, Van Hecke W, De Cock P, Eyssen M, De Weerdt W, Feys H. How does brain activation differ in children with unilateral cerebral palsy compared to typically developing children, during active and passive movements, and tactile stimulation? An fMRI study. Res Dev Disabil. 2012;34(1):183-97.

45. Nevalainen P, Pihko E, Maenpaa H, Valanne L, Nummenmaa L, Lauronen L. Bilateral alterations in somatosensory cortical 
processing in hemiplegic cerebral palsy. Dev Med Child Neurol. 2012;54(4):361-7.

46. Smorenburg AR, Ledebt A, Deconinck FJ, Savelsbergh GJ. Matching accuracy in hemiparetic cerebral palsy during unimanual and bimanual movements with (mirror) visual feedback. Res Dev Disabil. 2012;33(6):2088-98.

47. Lin KR, Prabhu V, Shah H, Kamath A, Joseph B. Handedness in diplegic cerebral palsy. Dev Neurorehabil. 2012;15(5):386-9.

48. •- Fazzi E, Signorini SG, Piana R LA, Bertone C, Misefari W, Galli J, Balottin U, Bianchi PE. Neuro-ophthalmological disorders in cerebral palsy. Dev Med Child Neurol. 2012;54(8):730-6. A thorough prospective look at vision disorders in children with a variety of types of cerebral palsy.

49. Van Genderen M, Dekker M, Pilon F, Bals I. Diagnosing cerebral visual impairment in children with good visual acuity. Strabismus. 2012;20(2):78-83.

50. Reid SM, Modak MB, Berkowitz RG, Reddihough DS. A population-based study and systemic review of hearing loss in children with cerebral palsy. Dev Med Child Neurol. 2011;53(11): $1038-45$.
51. Synnes AR, Anson S, Baum J, Usher L. Incidence and pattern of hearing impairment in children with $<800 \mathrm{~g}$ birthweight in British Columbia, Canada. Acta Paediatr. 2012;101(2):e48-54.

52. Dahlseng MO, Anderson GL, et al. Gastrostomy tube feeding of children with cerebral palsy variation across six European countries. Dev Med Child Neurol. 2012;54(10):938-44.

53. Nishiwaki S, et al. Predominant copper deficiency during prolonged enteral nutrition through a jejunostomy tube compared to that through a gastrostomy tube. Clin Nutr. 2011;30:585-9.

54. Beck JA, Glick N. Copper deficiency anemia and neutropenia in a jejunostomy-fed patient. PM R. 2009;1(9):887-8.

55. International Society for Clinical Densiometry-Official Position on Pediatrics. 2007. http://www.iscd.org/official-positions/. Accessed Feb 2013.

56. Fehlings $\mathrm{D}$, et al. Informing evidence-based clinical practice guidelines for children with cerebral palsy at risk of osteoporosis: a systematic review. Dev Med Child Neurol. 2012;54(2):106-16. 